\title{
Os conhecimentos de base para intervenção pedagógica do treinador de surf
}

http://dx.doi.org/10.11606/1807-5509201700040807

\author{
Vinicius Zeilmann BRASIL* \\ Valmor RAMOS* \\ Filipy KUHN* \\ Jeferson Rodrigues de SOUZA* \\ Juarez Vieira do NASCIMENTO**
}

${ }^{*}$ Centro de Ciências

da Saúde e do

Esporte, Universidade

do Estado de

Santa Catarina,

Florianópolis, SC,

Brasil.

\section{Resumo}

0 objetivo do estudo foi verificar a percepção de formadores de treinador de surf a respeito dos conhecimentos de base para a intervenção pedagógica nesta modalidade. Foi realizado um estudo qualitativo de casos múltiplos, com 5 formadores, com idades entre 36 e 45 anos, com experiência como treinador e formador de treinadores. Os dados foram coletados a partir de entrevista semiestruturada e analisados com a técnica de análise de conteúdo. Os resultados obtidos permitiram a indicação de um conjunto de conceitos que representam os conhecimentos valorizados pelos formadores, para a intervenção do treinador de surf, destacadamente, os conhecimentos específicos sobre esta modalidade, sobre as ciências do esporte, sobre os aprendizes, dos objetivos e papéis do treinador, e também o conhecimento para estabelecer relações interpessoais. Conclui-se que o risco inerente à prática desta modalidade exige do treinador de surf um conhecimento pedagógico para manter um ambiente favorável a aprendizagem, ao mesmo tempo em que preserva as sensações de aventura inerentes a esta prática.

Palavras-chave: Educação Física e Esporte; Formação Profissional; Treinador de Surf.

\section{Introdução}

O surf é uma das várias modalidades que têm sido identificadas como esporte de aventura. Esta denominação é atribuída à um conjunto de práticas esportivas caracterizadas pela interação do praticante com a natureza, a valorização pessoal dos próprios desafios, a exigência de uma "consciência" dos riscos inerentes a prática e também, pela possibilidade do praticante estar, relativamente, isento de regras rígidas de conduta, favorecendo a independência e autonomia para a prática ${ }^{1-3}$.

Estas características atribuem um nível de complexidade e dinamismo que diferenciam o contexto de intervenção profissional do treinador de surf em comparação aos treinadores de esportes tradicionais ${ }^{4,5}$. Predominantemente, a intervenção do treinador de surf tem estado ligada à orientação no âmbito do lazer e também da iniciação esportiva sistemática infantil, para jovens e também, para adultos denominada de iniciação tardia por SiLva et al. ${ }^{6}$ Estas possibilidades de intervenção no surf, são identificadas como contextos do Esporte Participação, o qual possui ênfase na prática esportiva para pessoas de todas as idades; e o Esporte Instrucional, fazendo referência aos contextos em que a orientação do treinador é para indivíduos de diferentes níveis de prática que buscam uma vivência esportiva episódica ${ }^{7,8}$.

Inúmeros desafios têm sido encontrados para a delimitação e definição de uma identidade profissional para o treinador de esportes de aventura $^{2,4}$, destacadamente, a definição de um conjunto de conhecimentos (competências/ habilidades) de base para a intervenção nesta área ${ }^{4}$, em particular no surf.

Propor uma estrutura conceitual, contextualmente válida, que indique os conhecimentos que sustentam a prática pedagógica do treinador esportivo é um dos desafios mais recorrentes na agenda investigativa nesta área ${ }^{9-11}$. O propósito dos estudos é fornecer algum direcionamento aos programas de formação 
de treinadores esportivos e também aos cursos de ensino superior em Educação Física e Esporte, sobre quais conhecimentos priorizar nestes contextos de formação de treinadores ${ }^{12,13}$. Além disso, a preocupação é como melhor estruturar o conhecimento do treinador, a exemplo das propostas do "Coaching Model"14 (Modelo do treinador) e do "Coaching Schematic"15 (Esquema do treino).

A abordagem dos estudos reflete a valorização do paradigma de pesquisa emergente do contexto de investigação e formação profissional do professor, influenciado pela psicologia cognitiva nas últimas décadas ${ }^{16-18}$. Ao invés de se estudar apenas "o que as pessoas fazem" (comportamento), este paradigma passa a incluir o estudo do "porque fazê-lo" (pensamentos) $)^{19}$. Os "pensamentos", nesta perspectiva, correspondem ao que os profissionais pensam ou sentem, incluindo as atitudes, a tomada de decisão, as percepçóes e os conhecimentos que possui.

No caso do treinador, esta abordagem prioriza decifrar o que está "por trás" de suas açóes pedagógicas ${ }^{19,20}$, sobretudo, as características específicas do conhecimento do treinador, sua estrutura conceitual e os processos decisórios em todas as dimensóes de sua intervençáa ${ }^{21}$. A relevância e possibilidade de teorizaçáo dos resultados oriundos das pesquisas desta linha de investigação está diretamente relacionada à qualidade do processo interativo entre o investigador e o sujeito da pesquisa, e também a procedência das informaçóes analisadas ${ }^{20,22}$.

De modo geral, as investigaçóes nesta área têm sido conduzidas a partir de abordagens qualitativas e com a utilização de técnicas como entrevistas, observação, grupo focal, e mais recentemente a partir da proposta dos mapas conceituais de Joseph Novak $^{13,19,22}$.

A abordagem dos mapas conceituais, em particular, destaca-se pela robusta fundamentação na teoria cognitiva da aprendizagem significativa de AUSUBEL $^{23}$; pela possibilidade de verificar, construir e registrar conhecimentos sobre determinado tema e também, de promover associaçóes entre "antigos" e "novos" conhecimentos ${ }^{24-26}$. No âmbito do treino esportivo, já se verifica alguma iniciativa nesta perspectiva, a exemplo, os estudos realizados por DowDELL ${ }^{27}$ para verificar a percepção de treinadores de ginástica sobre a eficácia no treino esportivo, e o de $\operatorname{VoHLE}^{28}$ que avaliou as estratégias de ensino em um curso para formadores de treinador de tênis de mesa.

Embora seja visível à inserção social do treinador de esportes de aventura, o desenvolvimento científico obtido nos estudos sobre o treinador de modalidades convencionais não parece ter implicaçóes ou influências diretas na prática pedagógica dos treinadores de surf, por exemplo ${ }^{2,3}$. No Brasil, apesar do treinador de surf estar legalmente vinculado a área da Educação Física, percebe-se ainda uma lacuna a respeito das investigaçóes acerca da intervenção e formação profissional relacionadas a este esporte ${ }^{29}$. Assim, o objetivo do presente estudo foi investigar as percepçóes de formadores de treinador de surf a respeito dos conhecimentos necessários para a intervenção pedagógica nesta modalidade.

Destaca-se, que o interesse é na "opinião" de profissionais, com alto nível de conhecimento acerca desta modalidade, sobre fatos, descrições e conceitos que fundamentam a intervenção do treinador de surf.

\section{Método}

Realizou-se uma investigação com abordagem qualitativa, do tipo descritivo, de caráter interpretativo ${ }^{30}$, a partir do estudo de casos múltiplos $^{31}$, com formadores de treinador de surf.

\section{Sujeitos do estudo}

Participaram do estudo 5 formadores de treinador de surf, 3 do sexo masculino e 2 do sexo feminino, selecionados de forma intencional ${ }^{32}$, tendo como primeiro critério de inclusão estar vinculado há alguma entidade esportiva brasileira, organizada juridicamente, que oferece programa de qualificação profissional para o ensino do surf, assim como, estar atuando como formador e também, na instrução desta modalidade para crianças, jovens e adultos, no período de realização do estudo. Além disso, adotaram-se critérios semelhantes aos utilizados em estudos sobre o conhecimento de treinadores de outras modalidades, desenvolvidos por CôTÉ et al. ${ }^{14}$ e AвrAнам et al..$^{15}$, nomeadamente: a) experiência de prática profissional como treinador de surf de no mínimo 10 anos; b) possuir experiência de prática profissional como formador de no mínimo 5 anos; 
c) reconhecimento de seus pares a respeito do conhecimento que possui sobre o ensino do surf; d) registro em algum Conselho Regional de Educação Física (CREF); e) disponibilidade e motivação para participar do estudo.

Este procedimento se deu por meio da consulta direta as entidades esportivas do surf, treinadores de surf e aos próprios formadores. Após a etapa anterior, realizou-se contato por telefone com os formadores indicados, para comunicá-los sobre a realização da pesquisa e interrogá-los a respeito de sua experiência de prática profissional (treinador e formador), intervençáo profissional atual e ainda, sobre sua disponibilidade e motivação para participar do estudo. Para preservar o anonimato dos investigados, adotaram-se letras e números (F1, F2, F3, F4 e F5) para identificação dos dados de cada sujeito no texto.

\section{Instrumentos de obtençáo dos dados}

Para a coleta dos dados foram utilizados um roteiro de entrevista semiestruturada e o registro pessoal do investigador por meio de um diário de campo. $\mathrm{O}$ roteiro da entrevista foi composto por 31 questôes, com possibilidades de respostas abertas para obter dados sobre os formadores e sobre sua percepção referente aos conhecimentos necessários para o ensino do surf. Nesta parte da entrevista utilizou-se como referencial os estudos de AвraHam et al..$^{15}$ sobre o conhecimento do treinador esportivo, e também o de Collins e Collins ${ }^{2}$ a respeito do conhecimento do treinador de esportes de aventura. Embora a formulação e ordem das questóes tenham sido estabelecidas a priori, o entrevistado pôde fornecer a resposta do modo como desejou (curta ou longa).

\section{Procedimentos de coleta dos dados}

Os sujeitos foram contatados por telefone, e-mail e pela rede social Facebook, para o agendamento (data, local e horário, de conveniência dos próprios treinadores) do primeiro encontro. Após o primeiro contato pessoal com os formadores (primeiro encontro) foram realizados mais três encontros para a realização das entrevistas, com duração média de 129 minutos (Mín. 69 minutos/ Máx. 209 minutos). A cada encontro com os formadores, foram abordados, novamente, os objetivos do estudo e os procedimentos de realização da entrevista.

As informações foram captadas por meio de gravador digital, armazenadas em microcomputador (pessoal do pesquisador e institucional), transcritas posteriormente com auxílio dos programas Windows Media Player e do Microsoft Word. Para cada transcrição foi gasto um intervalo de tempo aproximado de 26 horas, gerando um documento com 65 laudas em média. Os equipamentos e procedimentos de pesquisa foram testados em estudo piloto com um treinador de surf, em condiçóes semelhantes aos dos sujeitos do estudo. O projeto de pesquisa foi avaliado por um comitê de ética em pesquisa com seres humanos de universidade pública brasileira e atendeu as normas de investigação exigidas (Parecer no 718.148). Todos os sujeitos assinaram o termo de consentimento autorizando a gravação e divulgação dos resultados sem fins lucrativos.

\section{Análise dos dados}

Para análise de casos múltiplos, cada caso foi examinado individualmente e, em fase posterior, foram confrontados entre si, permitindo o agrupamento dos resultados mais significativos em conformidade com a literatura consultada e as categorias do modelo de pesquisa adotado ${ }^{31}$. Embora as categorias principais de análise tenham sido previamente definidas, preservou-se a flexibilidade na utilização dos procedimentos de interpretação dos dados com o propósito de privilegiar a informação fornecida pelos formadores, conforme propóem CôtÉ et al. ${ }^{33}$ Desse modo, foram estabelecidas 6 componentes de conhecimento do treinador de surf, nomeadamente, o conhecimento dos papéis do treinador; dos objetivos da intervenção; específicos do surf; sobre os aprendizes; sobre as ciências do esporte; e ainda o conhecimento interpessoal. Estas categorias correspondem a conceitos gerais que retratam elementos e episódios do processo de treino a partir da percepção dos formadores.

A análise dos dados, portanto, foi realizada a partir da técnica de análise de conteúdo ${ }^{34}$, permitindo a produção de inferências organizadas e sistematizadas, do conteúdo obtido nas entrevistas com os formadores. Este processo deu-se em três fases: primeiramente, a transcrição das entrevistas; em segundo, a codificação das transcriçōes brutas em representaçóes de conteúdo identificando as unidades de significado em função das categorias de análise, e ainda, o agrupamento em um só local de todas as unidades de significado pertencentes a uma categoria; e em terceiro, a verificação das frequências das unidades de análise e a organização dos resultados. O programa QSR Nvivo 10 foi 
utilizado no processo de organização das unidades de significado e suas fontes.

Para a apresentação das informações utilizou-se a abordagem dos Mapas Conceituais, que corresponde a um modo de representação visual do conhecimento por meio de diagramas ${ }^{24,35}$, e que no estudo que se apresenta foi construído com o auxílio da ferramenta digital CmapTools.

Para conferir validade às descriçóes dos dados, foram empregados procedimentos de checagem pelos sujeitos investigados ${ }^{37}$. Assim, as descrições dos dados obtidos nas entrevistas foram enviadas aos sujeitos para que eles confirmassem a correspondência entre as informaçóes fornecidas nas entrevistas e as descrições realizadas pelo investigador. Para a validação de interpretação realizou-se a checagem "intrapesquisador" que consistiu na revisão das interpretaçôes de cada pesquisador por si mesmo; e checagem "interpesquisadores" na qual as transcriçóes foram analisadas por dois pesquisadores, e codificadas em unidades de significado que representavam as categorias gerais, havendo o confronto das interpretaçóes ${ }^{38}$.

Além disso, a realização das entrevistas em ambiente de trabalho dos formadores pode ter incentivado a ativaçáo de pensamentos e a emissáo de informaçóes mais detalhadas, conforme as indicações de CôtÉ et al. ${ }^{14}$ e Abraham et al. ${ }^{15}$.

\title{
Resultados e discussão
}

\author{
Caracterização dos formadores de treinador \\ de surf
}

TABELA 1 - Caracterização dos formadores de treinador de surf.

F: Formadores;

I: Idade; EPP:

Experiência de

Prática Pessoal;

EPT: Experiência

Profissional como

Treinador; EPF:

Experiência

Profissional

como Formador;

CP: Certificação

Profissional; QES:

Qualificação

Específica no Surf.

\begin{tabular}{ccccccl}
\hline F & I & $\begin{array}{c}\text { EPP } \\
\text { (Anos) }\end{array}$ & EPT & EPF & \multicolumn{1}{c}{ CP } & QES \\
\hline F1 & 43 & 32 & 18 & 10 & $\begin{array}{l}\text { Graduado em Turismo e Ho- } \\
\text { telaria. } \\
\text { Pós-graduado em surf. } \\
\text { Provisionado em Educação Fí- } \\
\text { sica para intervenção no surf. }\end{array}$ & $\begin{array}{l}\text { Certificaçáa em curso específico de surf; cer- } \\
\text { tificaçáo em curso de salvamento com pran- } \\
\text { cha (salva surf). }\end{array}$ \\
\hline
\end{tabular}

Certificação em cursos de instrutores de surf oferecidos pela National Surfing Schoolastic Association (EUA), British of Surfing Association (Inglaterra) e Surfing-Australia.

Instrutor de mergulho certificado pela Confederaçâo Brasileira de Pesca e de Despor-

F3 $45 \quad 3927 \quad 10$ Provisionado em Educação Fí- tos Subaquáticos (CBPDS); certificação em sica para intervenção no surf. curso de atendimento pré-hospitalar (Cruz Vermelha), e salvamento com prancha (salva surf).

Certificação em curso de instrutores de surf da International Surfing Association (ISA) e Surfing-Austrália, curso de salvamento aquático da First Aid \& Rescue Australia e o Bronze Medalion Certificate; curso de Administração, Marketing e Gestão de Negócios em Surf (USP).

Curso de salvamento aquático da First Aid \& Rescue Australia e o Bronze Medalion Certificate; curso de Administração, Marketing e Gestão de Negócios em Surf (USP). 
No presente estudo, embora o interesse tenha sido investigar casos de formadores que atuam em programas de qualificação de treinadores de surf, é importante destacar que todos os sujeitos selecionados (F1, F2, F3, F4 e F5), no momento de realização da pesquisa, contavam com relevante experiência como treinador, e, além disso, ainda desempenhavam esta atividade profissional.

De fato, isto vai ao encontro das proposiçóes de Cushion et al. ${ }^{20}$ a respeito dos estudos sobre os conhecimentos do treinador esportivo, em particular, ao que denominaram de Models of Coaching (modelo do treinador). As investigaçôes nesta perspectiva são realizadas com treinadores de sucesso ou experts, com foco na identificação dos conhecimentos dos treinadores, buscando a representação mental do processo de ser treinador a partir da experiência prática do próprio treinador. Segundo os autores, estas pesquisas podem garantir um caráter situado aos dados coletados, isto é, originários de episódios e situaçóes da prática, conferindo assim alguma validade ecológica as informaçôes.

\section{A percepçáo dos formadores sobre os conhecimentos do treinador de surf}

Os indicadores dos conhecimentos que os formadores mencionaram como necessários para a intervenção pedagógica do treinador de surf estão apresentados na FIGURA 1. O conceito geral (Os conhecimentos para intervenção pedagógica no surf) está localizado no centro do mapa, de maneira que os demais conceitos se ramificam em direção aos extremos. É importante destacar que o propósito é na exposição de conceitos gerais para os mais específicos, e não nas relaçôes entre estes conceitos.

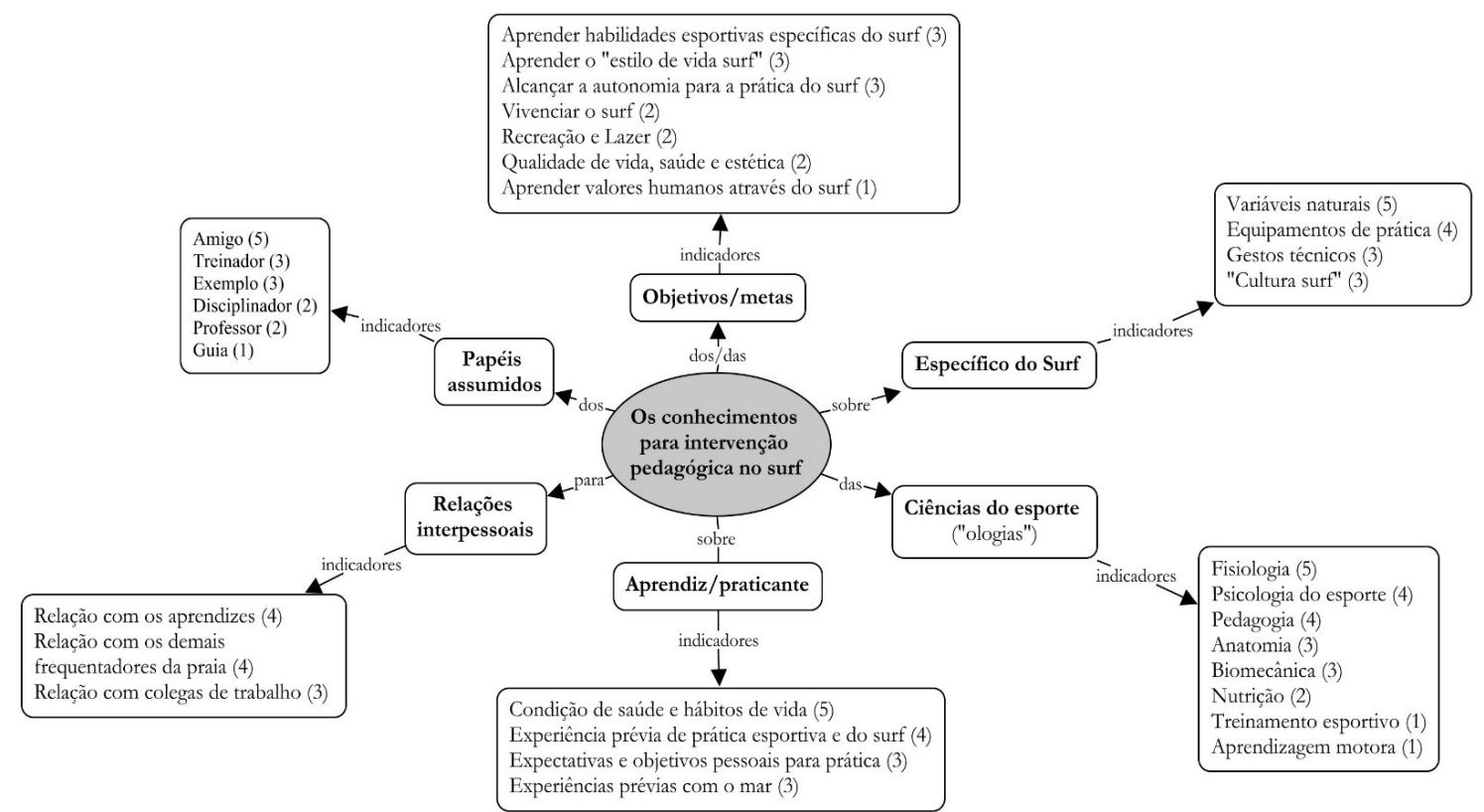

FIGURA 1 - Mapa conceitual sobre os conhecimentos para a intervenção pedagógica do treinador de surf, a partir da percepção dos formadores (frequência).

No que diz respeito ao conhecimento sobre os papéis que o treinador de surf pode assumir, os resultados indicam a unanimidade entre formadores para a percepção do papel de Amigo (5). A necessidade de o treinador fazer com que o aprendiz confie em sua orientação, sobretudo, por se tratar de uma prática em um ambiente instável, complexo, composto por muitos outros elementos "vivos" e naturais, implicando em risco para ambos, exige que o treinador se torne "um amigo porque ele acaba desenvolvendo um relacionamento de intimidade, de confiança com o aprendiz"(F4). Ademais, este papel está associado às orientaçóes que o treinador fornece ao principiante e que influenciam em suas atitudes, escolhas, e até mesmo a incorporação de valores de vida, isto é, um tipo de compartilhamento do "estilo de vida surf" ou "lifestyle".

Já os papéis de Treinador (3) e Exemplo (3) estão, respectivamente, ligados à função típica do treinador esportivo de fazer com que o aprendiz atinja bons desempenhos em relação à "técnica, a biomecânica, a capacidade física" (F3), e pelo mesmo demonstrar 
um tipo de "admiração" pela trajetória de prática pessoal e profissional do treinador, servindo como um modelo de valores e atitudes, ou seja: "é um cara que vai falar sobre alimentação saudável, sobre um estilo de vida bacana, sobre a natureza" (F4).

De acordo com Collins e Collins ${ }^{2}$ a delimitação dos papéis assumidos pelo treinador de esportes de aventura parece superar, em complexidade, as definiçóes utilizadas em contextos esportivos tradicionais. Segundo os autores, ao assumir como referência os motivos para a prática e o risco típico destas modalidades, este profissional, assume simultaneamente múltiplas identidades, como Guia, Treinador e Professor. O papel de Guia está ligado ao controle e "minimização" do risco de uma maneira prática, resguardando ao praticante o sentimento de diversão inerente a este tipo de prática. $\mathrm{O}$ papel de Treinador está associado a exploração do risco para manter a precisão contextual e garantir um grau de desafio ao praticante, favorecendo a aprendizagem de habilidades esportivas. Por fim, no caso do papel de Professor, faz referência às decisões e julgamentos deste, com o propósito de manter níveis adequados de percepção do risco (praticante), enquanto instrumento pedagógico para o desenvolvimento integral do aprendiz.

Com relação aos Objetivos que o treinador de surf deve estabelecer aos aprendizes, os resultados revelam uma valorização de objetivos relacionados ao domínio de habilidades esportivas específicas (3) que favoreçam o desempenho de prática do surf; ao aprendizado de um "estilo de vida surf" (3), ligado a um conjunto de comportamentos e valores que compóem a identidade deste grupo social (linguagem, modo de se vestir, alimentação, preferências musicais e de lazer, entre outros); favoreçam também, o ensino de informaçóes sobre o contexto amplo de prática que possibilite ao aprendiz alcançar certo nível de autonomia (3) para verificar a melhor praia e o local da praia mais adequado para prática, selecionar seu próprio equipamento, identificar os riscos e compreender as normas de segurança.

Estas interpretaçóes podem ser sustentadas nas proposições de Côté e GilberT ${ }^{39}$, de que a intervençáo do treinador deve gerar nos praticantes quatro tipos de resultados positivos, nomeadamente, competência, confiança, conexão e caráter. De fato, os objetivos estabelecidos pelo treinador devem permitir que os aprendizes desenvolvam sua personalidade, que se tornem construtivos e comprometidos consigo mesmo, e assim, um membro ativo da sociedade. Apesar de o treinador possuir alguma projeçáo do que o principiante aprenda, fica evidente na fala dos formadores que para a definição dos objetivos, sejam eles de curto, médio ou longo prazo, é fundamental considerar as características gerais do aprendiz (idade, sexo, experiência esportiva, hábitos de prática de atividade física) e também o que o aprendiz espera com a prática do surf, conforme afirma o formador F3:

"na verdade, é uma via de duas mãos. O principal objetivo do treinador deveria ser atender, primeiro, a expectativa do aprendiz. Então, a partir do momento que ele diz que a expectativa dele é subir na prancha, o treinador tem que estar focado para que ele suba na prancha. Tudo é uma questão de você estar muito consciente da expectativa daquela pessoa que está na tua frente ali, naquele momento".

De fato, a definição dos objetivos indicados pelos formadores, parece se aproximar de uma abordagem centrada no indivíduo que aprende, buscando atender as expectativas, as necessidades e as qualidades de cada um deles.

Os indicadores dos conhecimentos mencionados pelos formadores permitem destacar a preocupação desses profissionais com os conhecimentos específicos ou típicos do surf, exemplificado pela indicação de F1: "tem que saber tudo [...]. É por isso que eu digo né, o cara tem que ter uma vivência de vida inteira de surf" (F1).

Assim, por meio de uma interpretação sistêmica, o conhecimento específico sobre esta modalidade pode ser entendido a partir dos elementos de sua estrutura: o contexto, o equipamento e o praticante ${ }^{40,41}$.

O conhecimento sobre o contexto faz referência as variáveis naturais (5) e demais aspectos que envolvem a "cultura surf". Particularmente, ao espaço imediato de prática, na percepção dos formadores, o treinador "tem que saber de ondulação, tem que saber de vento, tem que saber de bancadas, que tipos de ondas existem" (F2). Além disso, eles salientam a importância de saber como todas estas variáveis interagem, ou seja, como o comportamento de uma condiciona o da outra (a prioridade é saber como as demais variáveis condicionam a onda, sua textura, o tamanho, a velocidade, a inclinação, a força, e a sua extensão).

A respeito dos conhecimentos sobre os equipamentos (4) utilizados na prática do surf, foi igualmente atribuída importância pelos formadores, como mesmo afirma F2:

"Ele tem que ter ciência de todos os equipamentos que existem, todas as pranchas, leash ${ }^{\mathrm{a}}$, decks $\mathrm{s}^{\mathrm{b}}, e$ tudo mais que diferencie um do outro. Tem que ter 
noção total de tudo que é equipamento para você poder passar para o cara, eu acho muito importante você ter total ciência de todos os equipamentos do surf, tanto das antiguidades quanto das novidades, porque tudo é conhecimento e é curiosidade também" (F2).

O treinador de surf deve ser capaz de identificar os tipos de equipamentos, sua composição, medidas, durabilidade e funcionalidade, e ainda, as implicaçôes de cada um destes aspectos na funcionalidade do equipamento, e também como combiná-los para se atingir determinado "estilo de surf".

O conhecimento acerca do praticante abrange todos os aspectos (motores, cognitivos, físicos, afetivos) que podem levá-lo ao êxito durante a prática do surf e, na sua relação com o equipamento e com o contexto. Os gestos técnicos do surf (3), segundo os formadores, são indispensáveis ao treinador, isto é, "o cara tem que ser um praticante de surf.. conhecer a prática... ter o conhecimento da técnica aplicada"(F3). Embora não haja na literatura uma delimitação consensual sobre as técnicas do surf, os estudos de Moreira ${ }^{1}$, Silva ${ }^{42}$ e Correia ${ }^{43}$ indicam ser possível classificar as habilidades em três grupos: habilidades aquáticas aplicadas ao surf (movimentos de flutuação, propulsão, giros, imersōes e respiração em meio líquido); habilidades básicas ou fundamentais do surf (remar, sentar na prancha, ficar em pé na prancha); e as manobras básicas que correspondem aos movimentos do surfista durante o deslize na posição em pé ("cavada"/ bottom turnc, "batida"/ off the li $p^{\mathrm{d}}$, "rasgada"/ cutback").

O conhecimento sobre as ciências do esporte corresponde aos conhecimentos científicos ou teóricos, que segundo Abraham et al. ${ }^{15}$ e Côté e GILBERT $^{39}$, também podem ser colocados sob o título de "ologias", representam os componentes básicos das ciências do esporte, nomeadamente, a Fisiologia, Psicologia, Pedagogia e a Biomecânica. Embora não tenha sido apresentada uma razáo explicita para o treinador de surf ter domínio destes conhecimentos, é provável que estes sejam úteis enquanto um tipo de "apoio" aos treinadores para sua intervenção, auxiliando na forma de "repassar o conhecimento por meio de uma linguagem apropriada" (F3) e em outros aspectos também, como afirmam abaixo F2:

"Eu percebia que às vezes a biomecânica do cara não era a que eu queria que fosse, porque o cara tinha algum problema anatômico... então a anatomia, a fisiologia, o que eu estudei na universidade eu pude usar para que aumentasse o meu conhecimento, para poder passar tudo para o aprendiz... então eu acho que quanto mais conhecimento ligado ao esporte geral você tem, melhor vai ser para você poder passar isso para o seu aluno".

Estes conhecimentos mencionados pelos formadores parecem servir de base para a intervenção pedagógica do treinador de surf. De acordo com Mesquita ${ }^{44}$, estes conhecimentos são denominados de organizaçáo do processo de ensino-aprendizagem do esporte ou do treino, a qual implica fundamentalmente em: planejar (objetivos e seleçáo dos conteúdos); realizar (atividades de ensino, gestão, comunicação), avaliar; (análise dos resultados obtidos e "controle"); organizar a instrução (análise da situação/tomada de decisão/ aplicação) a ser fornecida aos aprendizes.

Além disso, é consenso na literatura atual, independente do contexto de atuação e da modalidade, a importância dos conhecimentos que dizem respeito aos processos fisiológicos corporais; aos princípios biomecânicos do movimento humano; aspectos psicológicos que influenciam a prática esportiva; e também o modo como os indivíduos aprendem $^{13,39}$.

A percepçáo dos formadores relativa ao conhecimento que o treinador de surf deve possuir a respeito de quem aprende indica para três direcionamentos principais. Há uma preocupação relacionada às informaçốes sobre a saúde e os hábitos de vida do aprendiz (5); assim como a preocupação sobre as experiências prévias no esporte e no surf (4); e ainda as expectativas do praticante acerca da prática do surf (3).

De acordo com F1 o treinador necessita saber: "se o cara pratica esporte; se ele pratica, e qual é o nivel; se ele é sedentário; se ele tem problema de saúde, alguma patologia; se ele já fez algum esporte com prancha também... sobre o objetivo do cara, ver qual é a ideia dele... entender psicologicamente se o cara gosta de fazer uma coisa mais pegada, mais puxada ou mais devagar, se sabe nadar".

Segundo Ramos et al. ${ }^{45}$ o conhecimento sobre o aluno é um dos componentes de base para intervenção pedagógica e que expressa o entendimento sobre as características gerais do aprendiz, seus interesses, seus comportamentos, suas crenças e valores. No caso dos treinadores de surf, estas informaçôes parecem servir como um tipo de balizamento para a sua intervenção, inclusive, segundo Collıns e Collins² , a motivação dos praticantes tem sido um dos aspectos considerados para a caracterização e definição da intervenção do treinador de esportes de aventura. 
O treinador de surf não intervém de modo isolado, mas a partir de interaçóes individuais e em grupo. Na percepção dos formadores, isso ocorre a medida em que o treinador interage com os aprendizes, com os pares, com os surfistas da praia em que atua, com os profissionais de salvamento aquático, conforme representado na fala de F3:

"Ele deve saber se relacionar com os colegas de trabalho, estabelecer um vinculo de confiança com quem ele está ensinando, uma boa convivência com os demais frequentadores da praia, um bom relacionamento com os fornecedores de equipamentos. Estabelecer uma boa relação humana no trabalho... ele precisa necessariamente, estabelecer uma boa relação de convivência, uma boa relação humana no trabalho... ética profissional".

Para Gilbert e Côté ${ }^{13}$ tratam-se de habilidades emocionais e sociais, que podem ser referenciadas como um aspecto "humano" do treinador, as quais viabilizam o complexo e recíproco processo de interaçóes sociais, presentes no contexto de atuação deste profissional, configurando-se como um tipo de conhecimento interpessoal.

A partir da interpretação das percepçóes dos formadores investigados é evidente o amplo repertório de conhecimentos que o treinador de surf deve possuir para intervir nesta modalidade. Pode-se inferir que a sugestão dos formadores é de que o treinador possua um domínio aprofundado sobre os conhecimentos específicos do surf (contexto/ praticante/equipamento) em combinação com os demais componentes de conhecimentos apresentados neste estudo (papéis; objetivos; sobre os aprendizes; ciências do esporte; interpessoal). De fato, a exigência é de que o treinador tenha bom nível de prática no surf de modo a operacionalizar sua intervenção pedagógica.

Estes indicativos vão ao encontro dos resultados encontrados nos estudos de CorreiA ${ }^{43}$ com 11 treinadores de surf portugueses experientes, e mais recentemente o de RAMOs et al. ${ }^{5}$ com 11 treinadores brasileiros da mesma modalidade. Os treinadores indicaram a importância significativa da experiência de prática do surf para realizaçáo de todo o processo de intervenção pedagógica nesta modalidade. Do mesmo modo, PAIXÃO ${ }^{4}$, ao investigar a formação e desempenho profissional de 109 treinadores de diferentes modalidades esportivas praticadas na natureza, verificou a valorização do domínio das habilidades específicas do esporte; a "intimidade" com o equipamento e sua manutenção; a conscientização sobre os riscos envolvidos; e a utilização da tecnologia disponível para a prática. Ainda mais, aspectos como a técnica específica do esporte, a manipulação correta dos equipamentos, a consciência do ambiente natural e os procedimentos necessários para o controle de risco, podem garantir a integridade do treinador e do aprendiz num ambiente que oferece risco.

Pode-se interpretar que o conhecimento do treinador de surf inclui um tipo de conhecimento declarativo (teórico), relativo as ciências do esporte ("ologias"), de caráter específico do surf e, sobre os conhecimentos pedagógicos de intervenção. Por outro lado, devem ser acompanhados de um outro tipo de conhecimento processual (prático), para a realização das açóes pedagógicas, conforme ICCE ${ }^{8}$, Côté et al. ${ }^{14}$, Авraham et al. ${ }^{15}$, Côté e Gilbert ${ }^{39}$, Nash e Collins ${ }^{46}$.

Segundo Côté e GiLBert ${ }^{39}$, os conhecimentos que sustentam a prática do treinador estão distribuídos em três componentes: Conhecimento Profissional (específico do esporte/modalidade, ciências do esporte e pedagógico) o qual define com precisão o corpo de conhecimento típico do treinador esportivo; Conhecimento Interpessoal (interaçóes com alunos/aprendizes, pais, dirigentes, mídia); e Conhecimento Intrapessoal (compreensão de si mesmo e da capacidade de introspecção e reflexão).

Esta proposta tem sido utilizada no "quadro conceitual" (framework) do International Council Coaching Excellence (ICCE) na orientação dos programas para a formação de treinadores em países como Canadá, África do Sul e Nova Zelândia. De acordo com as diretrizes publicadas pelo ICCE (2013), cada uma das categorias de conhecimento (profissional/interpessoal/intrapessoal), sugeridas por Côté e Gilbert ${ }^{39}$, servem como base das competências necessárias ao treinador para realizar seu trabalho.

Ao se propor algum direcionamento conceitual para orientar a intervenção do treinador de surf, é fundamental considerar como referência ao menos quatro fontes, nomeadamente, a percepçáo de treinadores (de competência reconhecida pelos pares) e/ou formadores, que no caso do presente estudo embora atuassem como tal também desempenhavam a função de treinador; a literatura especializada a respeito do treinador esportivo, incluindo as proposiçóes atuais sobre o treinador de esportes de aventura; as diretrizes dos currículos de formação inicial em Educação Física; e também as indicaçôes dos cursos federativos para a qualificação de treinadores de surf. 
Portanto, acredita-se que a abordagem conceitual, contemplada no presente estudo, pode ser um instrumento facilitador da aprendizagem, construção e compartilhamento de conhecimentos para a intervenção do treinador de surf. Os conceitos formulados a partir da percepçáo dos formadores investigados servem como "rótulos" ou símbolos, de caráter formal, que retratam aspectos do processo de intervir no âmbito do surf, e que podem fornecer um "guia" para: a construção de novos conhecimentos (ampliação dos mapas); estruturação curricular de programas de formação de treinadores; para o próprio treinador, orientado sua intervenção, aprendizagem e desenvolvimento profissional; e ainda, como um roteiro claro e validado para a realização de investigaçóes científicas a respeito do treinador esportivo.

É relevante destacar que embora os formadores investigados possuam percepções semelhantes sobre os conhecimentos necessários ao treinador de surf, cada um deles os "organiza" (integra), em sua estrutura cognitiva, de forma distinta, o que de fato náo se buscou contemplar no presente estudo.

A complexidade e o dinamismo envolvidos no contexto do surf reforçam o caráter adaptativo da atuação do treinador, exigindo a princípio, um engajamento pessoal fundamentado nas experiências armazenadas na memória dos próprios treinadores, e na compreensão de conceitos a respeito das funçôes exercidas. No caso particular deste estudo, a valorização dos conhecimentos dos formadores parece enfatizar a necessidade do conhecimento contextualizado para a pratica pedagógica dos treinadores, particularmente para os esportes de aventura na natureza.
A intervenção pedagógica no surf requer aos treinadores uma gama ampla de conhecimentos, sobretudo os que fazem referência ao ambiente de prática, aos gestos técnicos do surf, e aos equipamentos necessários para prática. Ademais, o risco inerente à prática desta modalidade compóe um cenário muito particular de intervenção, exigindo do treinador uma capacidade de, em pleno espaço de prática, realizar a gestão do risco para manter um ambiente favorável a aprendizagem, ao mesmo tempo em que preserva as sensaçôes de aventura inerentes a esta pratica.

Os conhecimentos mencionados pelos formadores vão ao encontro do que a literatura especializada tem indicado a respeito do conhecimento de base para o treinador esportivo, atribuindo validade científica aos conhecimentos dos sujeitos investigados. Desse modo, a apreciação dos resultados sobre estes conhecimentos pode implicar em importantes contribuiçóes para a formação de treinadores de surf, para futuras investigaçóes na área, e ainda na prática pedagógica dos treinadores. No contexto da formação profissional para intervir no surf, este repertório de conceitos, validado pelos formadores e em conformidade com a literatura, pode fornecer direcionamentos relevantes para estruturação curricular tanto nos programas oferecidos pelas entidades esportivas do surf; e também, nos cursos de formação inicial e pós-graduação na área da Educação Física e esportes. No âmbito da investigação, pode indicar possibilidades de investigaçáo sobre os conhecimentos do treinador de surf, e ainda na orientação teórica para a realização de pesquisas que consolidem os conhecimentos de base para o treinador, independentemente da modalidade.

\section{Abstract}

\section{The basic knowledge for pedagogical intervention of surf coach}

The aim of the present study was to verify the perception of surf coach developers about the knowledge base for the pedagogical intervention in this sport. The qualitative approach of multiple cases was the research design of this study. Five experienced surf coach developers, with ages ranging between 36 and 45 years old, composed the sample. A semi-structured interview guide was used for data collection and the technique of content analysis to data analysis. The results showed a set of concepts that represent the valued knowledge by developers for the surf coach intervention, especially, specific knowledge on surf, sports sciences, learners, coach goals and roles, and knowledge to establish interpersonal relationships. We conclude that the risk characteristic of this sport requires the surf coach a pedagogical knowledge for maintain a favorable environment to learning while preserving the adventure sensations provided by the surfing practice.

KeYwords: Physical Education and Sport; Professional Education; Surf Coach. 


\section{Notas}

a. Equipamento de segurança, feito de material elástico, que une a prancha ao tornozelo do surfista, também conhecido por strep.

b. Acessório de borracha aderente, utilizado na parte superior da prancha, dando aderência aos pés do surfista.

c. Virada ou curva na base da onda após o drop, definindo a direção a ser seguida (esquerda ou direita) e antecedendo as manobras.

d. Manobra onde o surfista após realizar uma cavada na base da onda, dirigi a prancha verticalmente em direção a crista da onda, atingindo um ponto de impacto onde possa colocar novamente a prancha de volta na parede da mesma, retornando ao seu percurso.

e. Curva realizada na parede da onda para voltar à parte com mais potência, próxima a espuma, marcando uma trajetória em “S”.

\section{Referências}

1. Moreira M. Surf: da ciência a prática. Lisboa: FMH; 2009.

2. Collins L, Collins D. Conceptualizing the adventure-sports coach. J Adv Educ Outdoor Learn. 2012;12(1):81-93.

3. Berry M, Lomax J, Hodgson C. Adventure sport coaching. London: Routledge; 2015. p. 357.

4. Paixão JA. Training and professional performance of radical sport instructors. Int J Sport Sci. 2013;3(6):198-203.

5. Ramos V, Brasil VZ, Goda C. O conhecimento pedagógico para o ensino do surf. Rev Educ Fís/UEM. 2013;24(3):381-92.

6. Silva RMP, Galatti LR, Paes RR. Pedagogia do esporte e iniciação esportiva tardia: perspectivas a partir da modalidade basquetebol. Pensar a Prática. 2010;13(1):1-13.

7. Duffy P, Hartley H, Bales J, Crespo M, Dick F, Vardhan D, et al. Sport coaching as a "profession": challenges and future directions. Int J Coach Sci. 2011;5(2):93-123.

8. International Council for Coaching Excellence. Association of Summer Olympic International Federations, Leeds Metropolitan University. International Sport Coaching Framework Version 1.2. Champaign: Human Kinetics; 2013.

9. Lyle J, Cushion C. Sports coaching: professionalisation and practice. Amsterdam: Elsevier; 2010.

10. Gilbert W, Rangeon S. Current directions in coaching research. Rev Iberoamericana Psicol Ejerc Deporte. 2011;6(2):217-35.

11. Rangeon S, Gilbert W, Bruner M. Mapping the world of coaching science: a citation network analysis. J Coach Educ. 2012;5(1);83-108.

12. Mesquita I. Contributo para a mudança de paradigma na formação de treinadores: razóes, contextos e finalidades. In: Bento JO, Tani G, Prista A, organizadores. Desporto e educação física em português. Porto: Universidade do Porto; 2010. p. 84-99.

13. Gilbert W, Côté J. Defining coaching effectiveness: a focus on coaches' knowledge. In: Potrac P, Gilbert W, Denison J. Routledge handbook of sports coaching. London: Routledge; 2013. p. 5-15.

14. Côté J, Salmela JH, Trudel P, Baria A, Russell SJ. The coaching model: a grounded assessment of expert gymnastic coaches' knowledge. J Sport Exercise Psy. 1995;7(1):1-17.

15. Abraham A, Collins D, Martindale R. The coaching schematic: validation through expert coach consensus. J Sport Sci. 2006;24(6):549-64.

16. Clark C, Peterson P. Teacher' thought processes. In: Wittrock M, editor. Handbook of Research on Teaching. $3^{\mathrm{a}} \mathrm{ed}$. New York: Macmillan; 1986. p. 255-96.

17. Graça A. Conhecimento do professor de educação física. In: Bento JO, Garcia R, Graça A, organizadores. Contextos da pedagogia do desporto. Lisboa: Livros Horizonte; 1999. p. 167-252.

18. Ramos V, Silva R, Brasil VZ, Vargas CR, Gutierres Filho PJB. Estudos sobre o pensamento do professor e a educação física: análise sinóptica. Pensar a Prática. 2011;14(3):1-18.

19. Gilbert W, Trudel P. Analysis of coaching science research published from 1970-2001. Res Q Exercise Sport. 2004;75:388-99.

20. Cushion CJ, Armour K, Jones R. Locating the coaching process in practice: models "for" and "of" coaching. Phys Educ Sport Pedag. 2006;11:83-99.

21. Lyle J. Sports coaching concepts: a framework for coaches' behavior. Routledge: London; 2002.

22. Culver D, Gilbert W, Sparkes A. Qualitative research in sport psychology journals: the next decade 2000-2009 and beyond. Sport Psychol. 2012;26:261-81.

23. Ausubel DP. A aprendizagem significativa: a teoria de David Ausubel. São Paulo: Moraes; 1982.

24. Moreira MA. Concept maps as tools for teaching. J Coll Sci Teach. 1979;8(5):283-86. 
25. Moreira MA. Mapas conceituais como instrumentos para promover a diferenciação conceitual progressiva e a reconciliação integrativa. Ciência e Cultura. 1980;32(4):474-9.

26. Novak JD. Learning, creating, and using knowledge: concept maps as facilitative tools in schools and corporations. New York: Routledge; 2010.

27. Dowdell T. Characteristics of effective gymnastics coaching. Sci Gym J. 2010;2(1):1524.

28. Vohle F. Cognitive tools 2.0 in trainer education. Int J Sport Sci Coach. 2009;4(4):58394.

29. Brasil VZ, Ramos V, Goda C. A produção científica sobre surf: uma análise a partir das publicaçóes entre 2000-2011. Revista Pensar a Prática. 2013;16(3):619-955.

30. Denzin NK, Lincoln YS, editores. O planejamento da pesquisa qualitativa: teorias e abordagens. 2a ed. Porto Alegre: Artmed; 2008.

31. Yin RK. Qualitative research from start to finish. New York: The Guilford Press; 2011.

32. Thomas JR, Nelson JK. Research methods in physical activity. 2a ed. Champaign: Human Kinetics; 1990.

33. Côté J, Salmela JH, Baria A, Russell SJ. Organizing and interpreting unstructured qualitative data. Sport Psychol. 1993;7(2):127-37.

34. Bardin L. Análise de conteúdo. Edição revista e ampliada. Lisboa: Edições 70; 2010.

35. Novak JD, Cañas AJ. Theoretical origins of concepts maps, how to construct, them, and uses in education. Reflect Educ. 2007;3(1):29-42.

36. Institute for Human and Machine Cognition. Cmap Tools software. Florida: IHMC; 2014 [citado em 2018 mar 14 ]. Disponível em: <https://goo.gl/v3qcnv>.

37. Silverman D. Interpretação de dados qualitativos: métodos para análise de entrevistas, textos e interaçóes. $3^{\mathrm{a}}$ ed. Porto Alegre: Artmed; 2009.

38. Gibbs G. Análise de dados qualitativos. Porto Alegre: Artmed; 2009.

39. Côté J, Gilbert W. An integrative definition of coaching effectiveness and expertise. Int J Sport Sci Coach. 2009;4(3):307-23.

40. Funollet F. Propuesta de clasificación de las actividades deportivas en el médio natural. Apunts. 1995;(41):124-9.

41. Brasil VZ, Ramos V, Terme AA. O surf como esporte moderno: uma proposta de taxonomia. Efdeportes. 2010;145(15):[8 p.].

42. Silva MRC. Contributo para uma sistematização das habilidades básicas na iniciação ao surf [dissertação]. Porto: Universidade do Porto, Faculdade de Desporto da Universidade do Porto; 2000.

43. Correia MCEE. Concepçóes didáticas e metodológicas do ensino do surf [dissertação]. Lisboa: Universidade Técnica de Lisboa, Faculdade de Motricidade Humana; 2005.

44. Mesquita I. A pedagogia do treino: a formação em jogos desportivos colectivos. Lisboa: Livros Horizonte; 2000.

45. Ramos V, Graça ABS, Nascimento JV. O conhecimento pedagógico do conteúdo: estrutura e implicaçóes à formação em educação física. Rev Bras Educ Fís Esporte. 2008;22(2):161-71.

46. Nash C, Collins D. Tacit knowledge in expert coaching: science or art? Quest. 2006;58(4):465-77.

\begin{tabular}{r|r} 
ENDEREÇo & \\
Vinícius Zeilmann Brasil & \\
Centro de Ciências da Saúde e do Esporte da & Recebido para publicação: 10/06/2015 \\
Universidade do Estado de Santa Catarina & Revisado: 06/01/2016 \\
Rua Delfino Conti, s/n - Campus Universitário & Aceito: 15/12/2016 \\
88040-900 - Florianópolis - SC - BRASIL & \\
e-mail: vzbrasil@hotmail.com &
\end{tabular}

